\title{
How SOLID is the immune system's response to the deadly duo of lung cancer and SARS-CoV-2?
}

\author{
Hiba Narvel ${ }^{1}$, Balazs Halmos ${ }^{2}$ \\ ${ }^{1}$ Department of Medicine, Jacobi Medical Center, Albert Einstein College of Medicine, Bronx, NY, USA; ${ }^{2}$ Department of Oncology, Montefiore \\ Medical Center, Albert Einstein College of Medicine, Bronx, NY, USA \\ Correspondence to: Balazs Halmos. Department of Oncology, Montefiore Medical Center, Albert Einstein College of Medicine, Bronx, NY, USA. \\ Email: bahalmos@montefiore.org. \\ Comment on: Provencio M, Rodríguez-Abreu D, Ortega AL, et al. Seroprevalence and immunological memory against SARSCoV-2 in lung cancer \\ patients: the SOLID study. Transl Lung Cancer Res 2022;11:53-63.
}

Submitted Feb 17, 2022. Accepted for publication Feb 25, 2022.

doi: $10.21037 /$ tlcr-22-130

View this article at: https://dx.doi.org/10.21037/tlcr-22-130

Assessing the impact of coronavirus disease 2019 (COVID-19) objectively in unique cohorts of patients is of key importance to guide policy and preventive strategies, however has been challenging and fraught with many biases. Patients with a lung cancer diagnosis are at particularly high risk during the COVID-19 pandemic as given frequently advanced age, multiple comorbidities and limited lung reserves, outcomes are poor (1). In addition, as many patients need to receive active oncologic treatment, they are frequently exposed to health care facilities and hence are at a higher risk of acquiring COVID infection. Also, ongoing and prior therapies such as chemotherapy and radiation can add to immune suppression and poor pulmonary reserve further escalating risk. However, the initially noted concerningly high mortality rates for COVID-19 patients tended to be obtained from hospitalized patients leading to selection biases as asymptomatic or mildly symptomatic cases were not considered (2,3).

Better understanding of the prevalence and impact of COVID-19 infection in broad cohorts of patients therefore is important and so is learning about how well immunity is sustained following initial infection over time. Recent data suggestive of re-infections both following prior COVID-19 infections as well as initial sets of vaccinations certainly has raised concerns about waning immunity now accentuated in the context of new variants, such as Omicron $(4,5)$.

Therefore, cross-sectional studies are important and this is what the study team of Provencio et al. set out to pursue in a large prospective cohort of patients with a diagnosis of lung cancer (6). Since there was a dearth of availability of diagnostic tests when this study was initiated in April 2020, serological testing for the nucleocapsid antibody (which is unimpacted by vaccinations raising anti-spike antibody levels) of patients from the outpatient oncology clinics seemed a suitable option to overcome selection bias (7). Of note is that given the timeframe of this study, the majority of the patients were unvaccinated in this cohort (8). The primary end points were to measure the prevalence and persistence of humoral immunity in lung cancer patients. Seroprevalence was measured in 1,500 patients with a second determination 4.5 months after the first, if the first assessment was positive to assess temporal changes in antibody levels. Rates of reinfection were measured amongst those patients who tested seropositive initially. Key variables, including treatment modalities associated with loss/persistence of antibodies were studied.

The study yielded a number of pertinent findings (Figure 1). Overall, seroprevalence in this patient cohort was found to be $8.5 \%$. In addition, morbidity and mortality associated with COVID-19 infection was low with only one death in the initially seropositive cohort over 4.5 months.

Only $47 \%$ of the initially seropositive patients had history of symptoms suggestive of COVID-19 infection highlighting the wide spectrum of manifestations of COVID-19 infections-from asymptomatic to fatal. A proportion of $69.2 \%$ of the initially seropositive subjects retained persistent seropositivity after 4.5 months, $75 \%$ of whom were actively receiving lung cancer treatment. The 


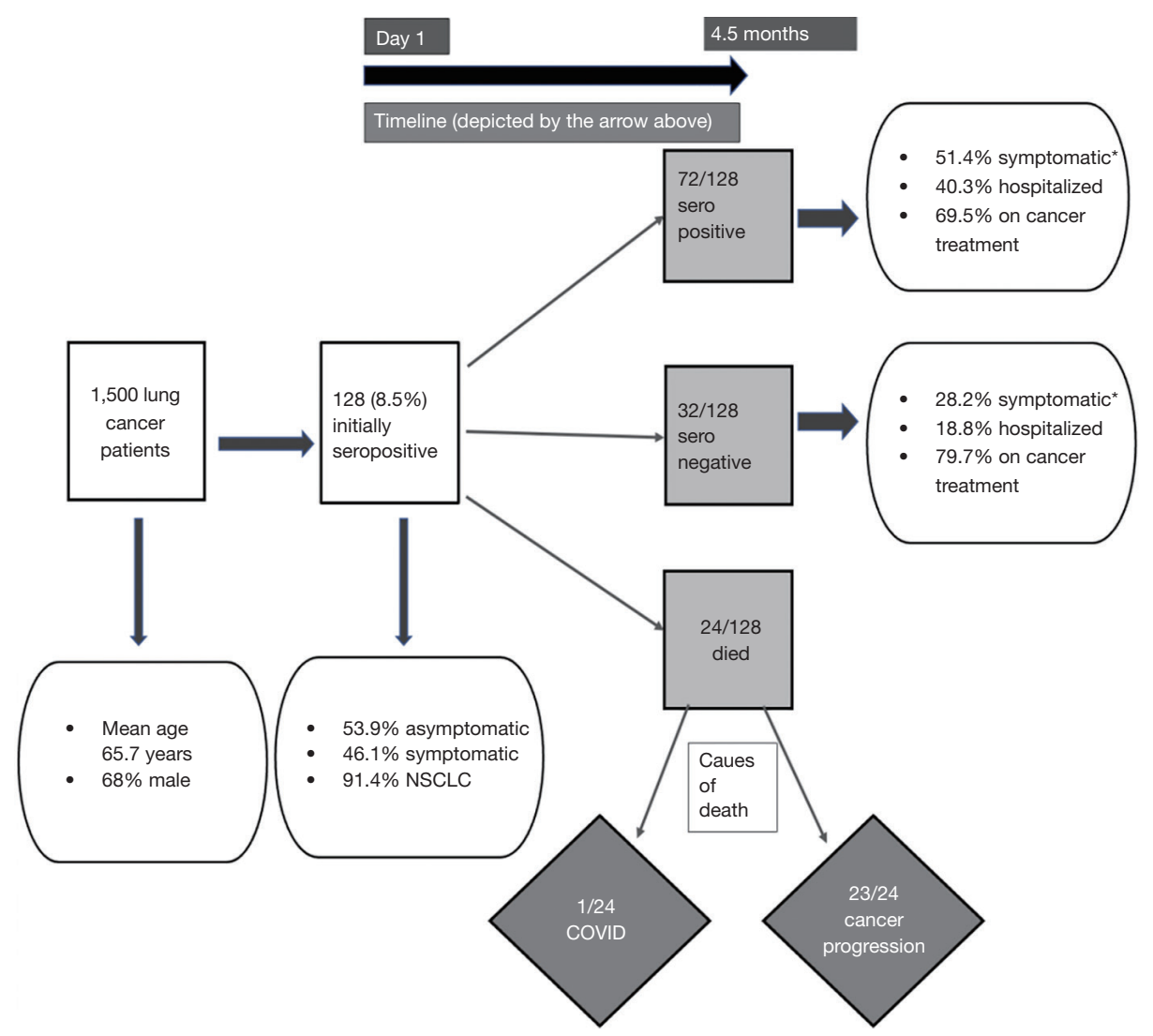

Figure 1 Pertinent findings of the study. *, symptomatic at diagnosis. NSCLC, non-small cell lung cancer.

specific treatment modality received or other variables were not associated with loss of nucleocapsid IgG positivity after 4.5 months, admittedly here numbers per treatment subset are small to reach strong conclusions. Lower rates of reinfection were found as anticipated in seropositive patients. Interestingly, $47 \%$ of patients $(n=49)$, had an increase in nucleocapsid antibody titers in the second determination. No statistically significant differences were found in any of the parameters analyzed between patients in whom antibody titers increased versus those in whom titers were maintained or decreased.

The authors overall conclude that "immunity" against severe acute respiratory syndrome coronavirus-2 (SARS$\mathrm{CoV}-2$ ) persists beyond 4 months. The severity of the infection, the need for hospitalization $(\mathrm{P}=0.032)$ and the presence of symptoms at diagnosis $(\mathrm{P}=0.02)$ were associated with the persistence of "immunity" in the second determination. Here the authors have used immunity and seroprevalence interchangeably. But seroprevalence is a detectable immune response and a crucial but imperfect correlate of immunity well indicated by the occurrence of re-infections. Although seropositivity can imply previous infection and perhaps presence of humoral immunity, it might not be indicative of all the other factors that play a role in immunity including the cell mediated response. In asymptomatic individuals, memory $\mathrm{T}$ cell responses maybe more prevailing than antibodies and may aid in recovery even in those with insufficient humoral immunity $(9,10)$.

Widely differing rates of seroprevalence suggestive of a prior COVID-19 infection have been reported throughout various studies. Although the seroprevalence of $8.5 \%$ in cancer patients noted in this study was comparable to the nationwide population based seroprevalence of $5 \%$ in Spain, it is interesting to highlight that this is much lower than other similar studies mentioned in Table 1 (15-17). The authors attributed this to the large sample size encompassing many regions of Spain in their study. But many other factors can explain this, such as the infectivity rate in the geographical region and the local pandemic status as well as particular risk of population examined. 
Table 1 Summary data of the studies about seroprevalence in oncological patients post vaccination

\begin{tabular}{|c|c|c|c|c|c|c|}
\hline Sample size & $\begin{array}{l}\text { Demographic and clinical variables: } \\
\text { percentage }(\%) \text { receiving active } \\
\text { oncological therapy, treatment } \\
\text { modalities }\end{array}$ & Place & $\begin{array}{l}\text { Seroconversion } \\
\text { rate }(\%)\end{array}$ & $\begin{array}{l}\text { Surrogate for } \\
\text { immunogenicity } \\
\text { for COVID-19 }\end{array}$ & $\begin{array}{c}\text { Seroprevalence } \\
\text { significantly different } \\
\text { among different treatment } \\
\text { modalities (CT and IT) }\end{array}$ & Authors \\
\hline 200 & $\begin{array}{l}\text { All cancers including solid and } \\
\text { hem malignancies; active cancer } \\
\text { treatment (67\%), CT (56\%) }\end{array}$ & USA & $94 \%$ & anti-S IgG & Yes & $\begin{array}{l}\text { Thakkar } \\
\text { et al. (11) }\end{array}$ \\
\hline 140 & $\begin{array}{l}\text { Solid tumors }(81 \%) \text {, hem } \\
\text { malignancies (19\%); active cancer } \\
\text { treatment }(63 \%) \text {; CT }(23 \%), \text { IT }(11 \%)\end{array}$ & $\begin{array}{l}\text { USA, } \\
\text { Switzerland }\end{array}$ & $94 \%$ & anti-S IgG & No & $\begin{array}{l}\text { Addeo } \\
\text { et al. (13) }\end{array}$ \\
\hline
\end{tabular}

Another factor can be COVID control measures which also vary in different cohorts and regions, for instance in the study by Fuereder et al., low seroprevalence was not only observed in cancer patients but also the staff working in the oncology clinic (18). Seroprevalence may also be underestimated when it is randomly measured in a short time period as in the cross-sectional study by Provencio et al. because false negative results are not inconceivable when the subjects may be tested outside the time window of most robust antibody response. Around $30 \%$ of the patients lost detectable antibodies after 4.5 months, most of whom were asymptomatic at diagnosis, so probably had low level of infection. While false positivity is a potential confounder as well, the specificity of the used nucleocapsid antibody test is reported to be very high mitigating this concern. The lower rates of infection during the study period in seropositive versus seronegative patients indeed indicates that the generated humoral and/or the cellular responses were likely effective to prevent secondary symptomatic infections.

It has been well established in the literature that the seropositivity of anti-SARS-Cov2 antibodies postCOVID-19 infections in solid tumors is similar to the general population, which aligns with the findings of Provencio et al. $(18,19)$. But there are exceptions to this, for instance Cabezón-Gutiérrez et al. found cancer patients to have a more robust immune response compared to the general population (31.4\% vs. $10 \%)$ and Ladoire et al. found greater increase in seropositivity between the first and second waves of the pandemic in France in healthcare workers compared to cancer patient $(16,19)$. This can be explained by more stringent COVID control measures in cancer patients and greater exposure to COVID patients amongst healthcare workers. Similar to multiple studies highlighting the immune response in unvaccinated oncological patients (listed in Table 2), the study team of Provencio et al. do not find major differences in seroprevalence dependent on the therapy received, albeit the numbers for subset analyses might be too small to reach robust conclusions. Treatment modalities for lung cancer also do not impact the survival after COVID-19 infection very significantly as seen in the TERAVOLT study (22). In fact, in the study by Cabezón-Gutiérrez et al., higher seroprevalence was found in patients actively receiving oncological treatment compared to those who were not (16). Disparities in seroprevalence based on treatment received were found by Yazaki et al. in Japan, N-IgG and S-IgG levels were significantly higher in cancer patients who received immune checkpoint inhibitors than in those who did not (21).

There is emerging data from the post COVID-19 vaccination immunity setting as well. Initial reports by Thakkar et al. and Addeo et al. encouragingly showed very high seroconversion rates closely matching the overall population amongst patients with solid tumors versus 


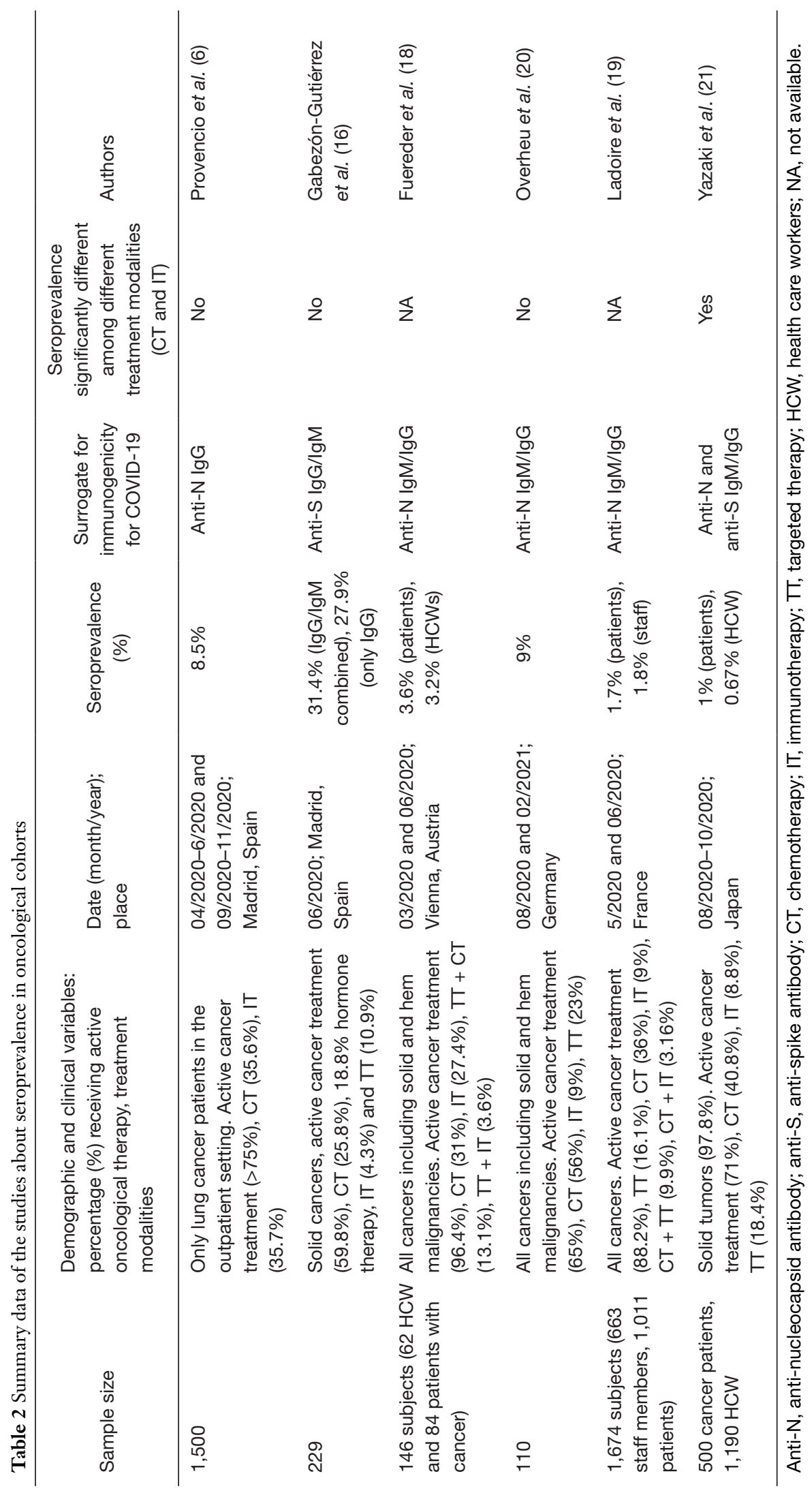


lower seroconversion rates in patients with hematological malignancies $(11,13)$. A subsequent study focusing on solid cancer patients did notice lower seroconversion rates post vaccination in patients on active treatment as compared to healthy controls $(\mathrm{P}=0.001)$ (14). Especially with lower seroconversion in patients receiving chemotherapy compared to other treatment modalities $(\mathrm{P}=0.02)(14)$. Thakkar et al. found that prevalence of nucleocapsid antibodies was less amongst patients with hematological malignancies and in particular following receipt of highly immune suppressive therapies, such as anti CD20, chimeric antigen receptor (CAR)- $\mathrm{T}$ cell treatments or stem cell transplantation but patients receiving immunotherapy showed higher seroconversion rates (anti-spike $\operatorname{Ig} G$ ) in response to COVID vaccination (11). This is likely due to greater immunosuppression by the treatment for hematologic malignancies compared to solid tumors which is also supported by more aggressive course and higher case fatality rates in COVID-19 infection in the former group (23).

While data is also emerging about vaccination-induced immunity, we certainly need to continue to invest into further research to understand correlations of serological detection of humoral and cellular immunity and risks and impact of breakthrough infections, in particular in light of new and potential variants. Overall, this important study provides relevant insights and an increasingly SOLID foundation into the overall detectability of prior COVID-19 infection amongst patients with a lung cancer diagnosis and provides longitudinal assessments informing us of waning immunity, risks of re-infections and highlights the strong need to focus on broad vaccinations to induce vaccinemediated immunity amongst this large and important group of at-risk patients.

\section{Acknowledgments}

Funding: None.

\section{Footnote}

Provenance and Peer Review: This article was commissioned by the editorial office, Translational Lung Cancer Research. The article did not undergo external peer review.

Conflicts of Interest: Both authors have completed the ICMJE uniform disclosure form (available at https://tlcr.amegroups. com/article/view/10.21037/tlcr-22-130/coif). The authors have no conflicts of interest to declare.
Ethical Statement: The authors are accountable for all aspects of the work in ensuring that questions related to the accuracy or integrity of any part of the work are appropriately investigated and resolved.

Open Access Statement: This is an Open Access article distributed in accordance with the Creative Commons Attribution-NonCommercial-NoDerivs 4.0 International License (CC BY-NC-ND 4.0), which permits the noncommercial replication and distribution of the article with the strict proviso that no changes or edits are made and the original work is properly cited (including links to both the formal publication through the relevant DOI and the license). See: https://creativecommons.org/licenses/by-nc-nd/4.0/.

\section{References}

1. Whisenant JG, Baena J, Cortellini A, et al. A definitive prognostication system for patients with thoracic malignancies diagnosed with COVID-19: an update from the TERAVOLT registry. J Thorac Oncol 2022. [Epub ahead of print].

2. Lièvre A, Turpin A, Ray-Coquard I, et al. Risk factors for Coronavirus Disease 2019 (COVID-19) severity and mortality among solid cancer patients and impact of the disease on anticancer treatment: A French nationwide cohort study (GCO-002 CACOVID-19). Eur J Cancer 2020;141:62-81.

3. Park R, Lee SA, Kim SY, et al. Association of active oncologic treatment and risk of death in cancer patients with COVID-19: a systematic review and meta-analysis of patient data. Acta Oncol 2021;60:13-9.

4. Schmidt AL, Labaki C, Hsu CY, et al. COVID-19 vaccination and breakthrough infections in patients with cancer. Ann Oncol 2022;33:340-6.

5. Zhang L, Li Q, Liang Z, et al. The significant immune escape of pseudotyped SARS-CoV-2 variant Omicron. Emerg Microbes Infect 2022;11:1-5.

6. Provencio M, Rodríguez-Abreu D, Ortega AL, et al. Seroprevalence and immunological memory against SARSCoV-2 in lung cancer patients: the SOLID study. Transl Lung Cancer Res 2021;11:53-63.

7. Wei J, Stoesser N, Matthews PC, et al. Antibody responses to SARS-CoV-2 vaccines in 45,965 adults from the general population of the United Kingdom. Nat Microbiol 2021;6:1140-9.

8. Available online: https://www.statista.com/topics/7616/ coronavirus-covid-19-vaccination-in-spain/ 
9. Sekine T, Perez-Potti A, Rivera-Ballesteros O, et al. Robust T Cell Immunity in Convalescent Individuals with Asymptomatic or Mild COVID-19. Cell 2020;183:158168.e14.

10. Bange EM, Han NA, Wileyto P, et al. CD8+ T cells contribute to survival in patients with COVID-19 and hematologic cancer. Nat Med 2021;27:1280-9.

11. Thakkar A, Gonzalez-Lugo JD, Goradia N, et al. Seroconversion rates following COVID-19 vaccination among patients with cancer. Cancer Cell 2021;39:10811090.e2.

12. Gounant V, Ferré VM, Soussi G, et al. Efficacy of Severe Acute Respiratory Syndrome Coronavirus-2 Vaccine in Patients With Thoracic Cancer: A Prospective Study Supporting a Third Dose in Patients With Minimal Serologic Response After Two Vaccine Doses. J Thorac Oncol 2022;17:239-51.

13. Addeo A, Shah PK, Bordry N, et al. Immunogenicity of SARS-CoV-2 messenger RNA vaccines in patients with cancer. Cancer Cell 2021;39:1091-1098.e2.

14. Ligumsky H, Safadi E, Etan T, et al. Immunogenicity and Safety of the BNT162b2 mRNA COVID-19 Vaccine Among Actively Treated Cancer Patients. J Natl Cancer Inst 2022;114:203-9.

15. Pollán M, Pérez-Gómez B, Pastor-Barriuso R, et al. Prevalence of SARS-CoV-2 in Spain (ENE-COVID): a nationwide, population-based seroepidemiological study. Lancet 2020;396:535-44.

16. Cabezón-Gutiérrez L, Custodio-Cabello S, PalkaKotlowska M, et al. Seroprevalence of SARS-CoV-2-

Cite this article as: Narvel H, Halmos B. How SOLID is the immune system's response to the deadly duo of lung cancer and SARS-CoV-2? Transl Lung Cancer Res 2022;11(2):126-131. doi: $10.21037 /$ tlcr-22-130 specific antibodies in cancer outpatients in Madrid (Spain): A single center, prospective, cohort study and a review of available data. Cancer Treat Rev 2020;90:102102.

17. Liu T, Zeng G, Tao H, et al. Low prevalence of IgG antibodies to SARS-CoV-2 in cancer patients with COVID-19. Int J Cancer 2020;147:3267-9.

18. Fuereder T, Berghoff AS, Heller G, et al. SARS-CoV-2 seroprevalence in oncology healthcare professionals and patients with cancer at a tertiary care centre during the COVID-19 pandemic. ESMO Open 2020;5:e000889.

19. Ladoire S, Goussot V, Redersdorff E, et al. Seroprevalence of SARS-CoV-2 among the staff and patients of a French cancer centre after first lockdown: The canSEROcov study. Eur J Cancer 2021;148:359-70.

20. Overheu O, Quast DR, Schmidt WE, et al. Low Serological Prevalence of SARS-CoV-2 Antibodies in Cancer Patients at a German University Oncology Center. Oncol Res Treat 2021. [Epub ahead of print].

21. Yazaki S, Yoshida T, Kojima Y, et al. Difference in SARSCoV-2 Antibody Status Between Patients With Cancer and Health Care Workers During the COVID-19 Pandemic in Japan. JAMA Oncol 2021;7:1141-8.

22. Garassino MC, Whisenant JG, Huang LC, et al. COVID-19 in patients with thoracic malignancies (TERAVOLT): first results of an international, registrybased, cohort study. Lancet Oncol 2020;21:914-22.

23. Başcı S, Ata N, Altuntaş F, et al. Patients with hematologic cancers are more vulnerable to COVID-19 compared to patients with solid cancers. Intern Emerg Med 2022;17:135-9. 